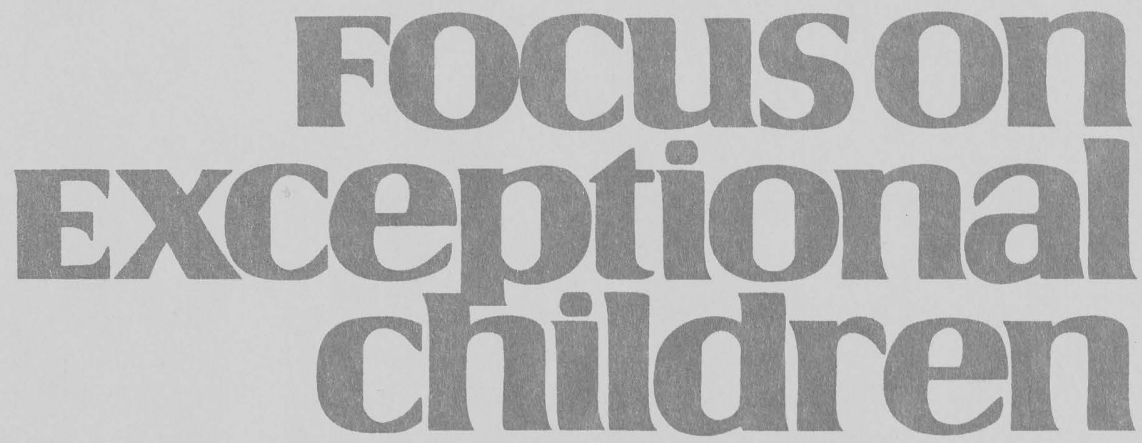

\title{
The Role of Instructional Planning in Math Instruction for Students With Learning Disabilities
}

\author{
Edward Meyen and Diana Greer
}

Instructional planning is an essential skill for teaching mathematics to students with learning disabilities and other struggling learners. The authors' frame of reference is based on their experiences in developing and testing mathematic lessons for the Blending Assessment With Instruction Program (BAIP) over a five-year period. The authors stress the view that in addition to possessing content knowledge, teachers must be proficient in translating their knowledge of curriculum standards into detailed instructional plans. Such planning is essential to the alignment of instruction with standards.

\section{INSTRUCTIONAL PLANNING}

It is common knowledge that students, especially students with learning disabilities, in the United States are not performing as well in mathematics as students in many other countries (Institute of Education Sciences [IES], 2006). What is less well known is whether teacher expertise contributes to these differences. According to the 2007 Trends in International Mathematics and Science Study (TIMSS), eight countries outperformed the United States in mathematics achievement at the fourth-grade level, and five countries outperformed the United States at the eighth-grade level (IES, 2007). These disparities reported in achievement not only exist internationally, but also exist between subgroups within the United States. Results from the National Assessment of Educational Progress (NAEP) (U.S. Department of Education, 2007) indicate a 21-point average scale score difference at the fourth-grade level and a 41-point average scale score difference at the eighth-grade level between the mathematic performance of students with and without disabilities.

Both national and international comparisons have caused many researchers to examine differences in the preparation of teachers in math content knowledge and instructional planning in the United States and other countries (Baroody, 2003; Fuson, Stigler, \& Bartsch, 1989; Ma 1999; Shen, Popink, Cui, \& Fan, 2007; Thompson, 2008). Studies have found that although teachers in other countries have completed fewer courses in mathematics during pre-service education than their counterparts in the United States, their classroom instructional effectiveness appears to be based on a wider breadth and depth of

Dr. Meyen is a Professor of Special Education at the University of Kansas. Dr. Greer is an Associate Researcher at the University of Kansas. Both authors are affiliated with the eLearning Design Lab.

The authors wish to acknowledge the contributions of the Center for Education Testing and Evaluation as well as the eLearning Design Lab staff. 
mathematics content knowledge (Baroody, 2003). This finding is consistent with Ma (1999), who found that although pre-service teachers in China had less preparation in mathematics than teachers in the United States, their mathematic knowledge was more profound, more flexible, and more adaptive. Differences between instructional effectiveness and mathematic content knowledge of teachers in the United States and China have been attributed, in part, to the amount of time teachers devote to developing, reflecting on, and modifying daily instruction (Shen, Popink, Cui, \& Fan, 2007). In China, teachers spend about four hours a day planning instructional lessons. As a result, teachers in China are seeking additional mathematic knowledge on an ongoing basis as they develop detailed lesson plans. By comparison, in the United States, the nature of lesson plan development tends to be brief and very general, often focusing exclusively on activity development or the identification of what should be taught from resources such as textbooks. This approach to lesson plan development does not require much reflection on the teachers' part nor does it contribute to the routine pursuit of additional knowledge acquisition.

\section{Focuson
Exceptional
children}

ISSN 0015-511X

FOCUS ON EXCEPTIONAL CHILDREN (USPS 203-360) is published monthly except June, July, and August as a service to teachers, special educators, curriculum specialists, administrators, and those concerned with the special education of exceptional children. This publication is annotated and indexed by the ERIC Clearinghouse on Handicapped and Gifted Children for publication in the monthly Current Index to Journals in Education (CIJE) and the quarterly index, Exceptional Children Education Resources (ECER). The full text of Focus on Exceptional Children is also available in the electronic versions of the Education Index. It is also available in microfilm from Serials Acquisitions, National Archive Publishing Company, P.O. Box 998, Ann Arbor, MI 48106-0998. Subscription rates: individual, \$48 per year; institutions, \$66 per year. Copyright (C) 2009, Love Publishing Company. All rights reserved. Reproduction in whole or part without written permission is prohibited. Printed in the United States of America. Periodical postage is paid at Denver, Colorado. POSTMASTER: Send address changes to:

Love Publishing Company

Executive and Editorial Office P.O. Box 22353

Denver, Colorado 80222

Telephone (303) 221-7333

\section{EDITORIAL BOARD}

Lisa Dieker

University of Central Florida
Paula Maccini University of Maryland
Marleen Pugach

University of Wisconsin-Milwaukee
National and international achievement comparisons have also caused many researchers to examine teacher quality within the United States (Brownell, Hirsch, Seo, 2004; Goldhaber, 2002; Hill, Rowan, \& Ball, 2005; Wayne \& Youngs, 2003). Teacher quality has been found to be one of the most important factors in explaining differences in student performance (Goldhaber, 2002). In fact, mathematic gains were found to be higher for students who were instructed by teachers who held certification in mathematics than by teachers who were not certified in mathematics (Goldhaber \& Brewer, 2000). In addition to content knowledge, successful mathematics instruction requires teachers to have a thorough understanding of students as learners and of pedagogical strategies-pedagogical content knowledge (Ball, Hill, \& Bass, 2005; Borko \& Whitcomb, 2008; Graham and Fennell, 2001; Shulman, 1987). Pedagogical content knowledge helps teachers "transform the content knowledge they possesses into forms that are pedagogically powerful and yet adaptive to the variation in ability and background presented by the students" (Shulman, 1987, p. 15). Thus, pedagogical content knowledge provides teachers with the ability to develop instructional lesson plans that incorporate different instructional approaches for each concept being introduced.

Historically, the preparation of special education teachers has tended to assume that the general classroom teacher is primarily responsible for teaching mathematics to students with learning disabilities. Thus, the traditional approach to the preparation of special education teachers in the United States has often focused on teaching collaboration, knowledge of effective interventions, and assessment. However, this trend must shift, as the instructional accountability model of today calls for highly qualified teachers, greater collaboration, and general education instruction and assessment inclusion for students with learning disabilities. Therefore, a strong case can be made that special education teachers need both content knowledge and rather sophisticated instructional planning skills to be effective in collaboration and in extending the instruction that children with disabilities require to be successful in meeting performance expectations. Therefore, the key to decreasing mathematic achievement gaps may be increasing teachers' content knowledge, instructional planning skills, and preparation in researchbased instructional practices in mathematics.

\section{The Context for the Authors Perspective}

The remainder of this paper sets forth an approach to instructional planning that evolved from work in the design, development, and testing of over 276 BAIP lessons in mathematics. Because of the extensiveness and detail of the instructional planning model that will be proposed, the authors have decided to share the development and application context 
that lead to the development and dissemination of the BAIP mathematic lessons. The intent is to provide a rationale for the authors' perspectives that is anchored in a particular set of experiences. A description of the BAIP lesson plan format is also provided.

The BAIP lesson plan format is based on 5 years of experience in working with over 100 educators, including classroom teachers, subject-matter experts in mathematics, and individuals skilled in educational technology. The BAIP is designed to assist teachers in aligning instruction with curriculum and assessment standards for all students. It consists of research-based lessons in mathematics for teachers and online tutorials for students which are aligned with standards in grades $3,4,5,6,7,8$, and high school. The authors' collective backgrounds are in special education, elementary education, instructional design, curriculum development, assessment, and teacher education. Their involvement in developing and researching the BAIP included collaborating with teachers and math educators with a focus on instructional design, content management, formative evaluation, development processes, management of technology production, and field testing.

The BAIP was pilot tested with 2,000 students in 2006-2007 and field tested in 2007-2008 in 187 school districts with 88,700 students, including 3,777 students with disabilities. After modifications, it was subjected to field testing in 229 school districts in 2008-2009. The interdisciplinary and collaborative approaches employed during lesson development and pilot testing have contributed to the authors' perspectives on the importance of teacher competencies in content knowledge and instructional planning. BAIP was developed by the eLearning Design Lab (eDL), which is a unit within the Center for Research on Learning (CRL), in collaboration with the Center for Educational Testing and Evaluation (CETE). The eDL was started as a partnership involving the CRL and the Information Technology and Telecommunications Center (ITTC) in Engineering in 1998. The lab began with a focus on teacher education with the support of the Online Academy (OSEP); however, over the past seven years the work of the lab has been migrating towards $\mathrm{K}-12$ elearning environments with an emphasis on the content areas of math and science. Over the history of the lab, development and production processes have been refined and validated. These processes are targeted to multiple approaches to quality control and assurance of scalability. The development team has been in place since the initial design work of BAIP. The lab has had remarkable stability among graduate students who come from fields such as special education, general education, computer science, engineering, architecture, instructional technology, and design. The content teams for the BAIP project are all selected through an extensive nomination process and review. The lab also works with freelance content developers.

Large-scale projects like BAIP have contributed to the development and validation of processes employed by the eDL for working with clients/collaborators in carrying out content- and technology-intense large-scale projects (Meyen, Aust, Bui, Ramp, \& Smith, 2002). An overview of the eDL development process model will be helpful to readers interested in the development environment in which the BAIP lessons were designed, developed, produced, and tested. Figure 1 illustrates the overall eDL development process model.

\section{Stage 1.0 Communications/User/Developer:}

Stages 1.0 and 2.0 are core development tasks that permeate each stage of development. For that reason, Stages 1.0 and 2.0 are presented in a vertical manner. The model illustrates how communication is integrated throughout all of the development stages. Communications between the eDL development team and users normally begins the moment first contact is made and continues throughout the

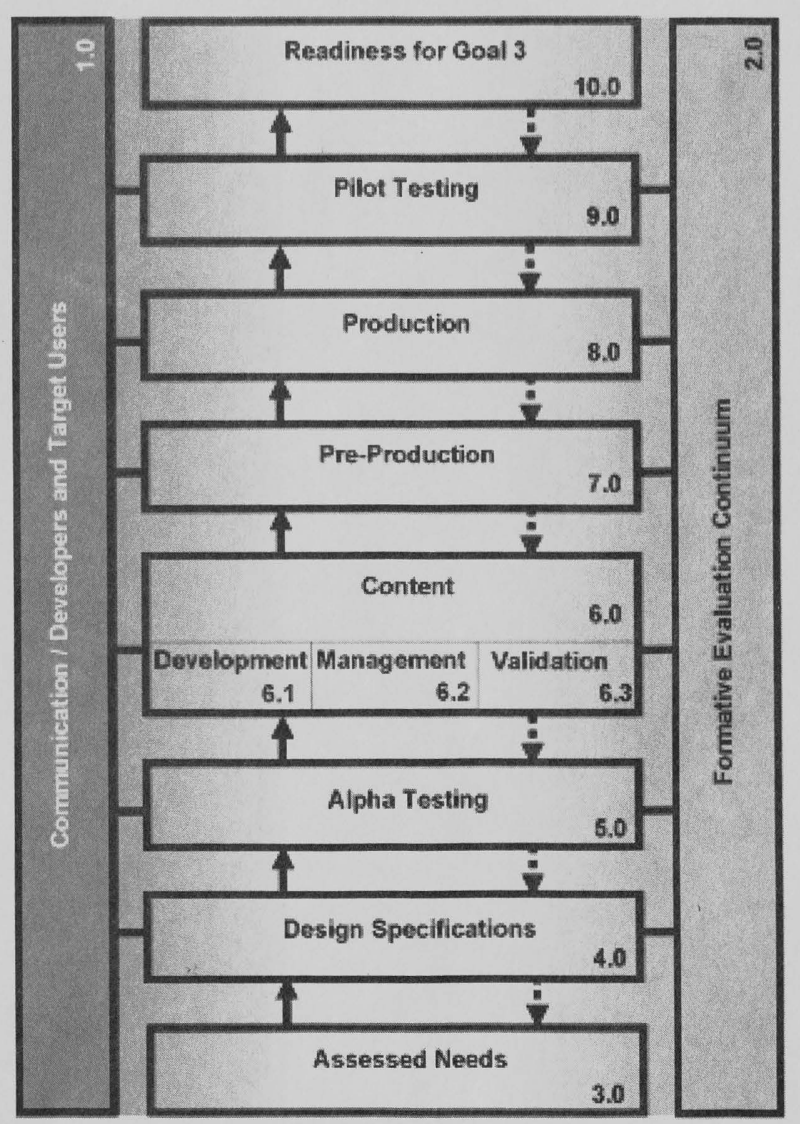

FIGURE 1. eDL Development Process Model 
project. This has been true throughout the BAIP development process. Initial communication concentrates on gaining an understanding of the authentic context in which the intervention(s) will be used. The most intense communication stages are at 3.0 (Needs Assessment), 4.0 (Design Specifications), 5.0 (Alpha Testing), 6.0 (Content Development and Management), and 9.0 (Pilot Testing). Although the production communication continues, the emphasis shifts to testing prototypes and refining what is produced based on design decisions and what is learned through the alpha testing of prototypes and associated procedures. This shift is reflected in the nature of communications from what is proposed for development to the refinement of what is being developed.

\section{Stage 2.0 Formative Evaluation Continuum:}

The design experiment approach to formative evaluation is central to each stage in the eDL development process. It is embedded at stage 2.0 as a vertical stage in the model to communicate its continuous application throughout development. The development process involves decision making at each stage in the process to ensure that the interventions being developed benefit from continuous monitoring and input from users. At each stage, input from teachers is gathered to ensure the interventions' applicability in authentic settings. Our approach in BAIP included student performance data derived from assessments embedded in each tutorial and student performance data from the annual state assessments.

\section{Stage 3.0 Assessed Needs:}

In the BAIP, the need emerged from the research of CETE over a period of twenty-five years to develop state level assessments in mathematics. The concern that assessment should be integrated with instruction was confirmed by teachers and subject matter experts.

\section{Stage 4.0 Design Specifications:}

This is a critical development stage, as it sets the parameters for the intervention design, production demands, schedule, time for completion, talent requirements, and costs. Once design features have been set, the eDL follows a process of developing tools (authoring systems) to facilitate production of products for projects intended to go to scale (Aust \& Meyen, 2005). The design specifications provide the framework to create the development tools and/or to modify the tools. Use of these tools (systems), or modified versions of them, saves the lab significant time and production cost. The tools for BAIP are closely guided by National Council of Teachers in Mathematics (NCTM) content standards, which consist of

1) Numbers and Operation Standard,

2) Algebra Standard,

3) Geometry Standard,
4) Measurement Standard, and

5) Data Analysis and Probability Standard.

\section{Stage 5.0 Alpha Testing:}

Alpha testing occurs whenever a component of an intervention reaches a functional stage. However, at certain steps in the development process, alpha testing is essential without being functional via technology (e.g., instructional designs). Under those conditions, alpha testing is formally done in Stage 5 but repeated as needed. Early alpha testing is typically done internally in a lab setting and carried out by individuals who are skilled in identifying deficiencies in products and relating them to the design specifications. Some alpha testing occurs in authentic settings. Structured pilot testing strategies focusing on authentic settings occur during Stage 9. BAIP was pilot tested early in a limited number of schools and then subjected to two consecutive years in large scale field-testing.

\section{Stage 6.0 Content Development/Management/Validation:}

For a project the magnitude of BAIP, detailed content management is critical. The tasks carried out at this stage generalize across content areas. The three major tasks related to content include:

6.1) Development: the actual development/creation of the content according to the specifications.

6.2) Management: the processing of the content through all stages of the development process (i.e., logging in receipt of the content, checking to be certain content is received for each element of the specifications, ensuring the content adheres to the design specification, providing feedback to content developers, editing the content, reviewing content by subject matter experts, and ensuring that the content is in final form prior to moving to the next stage, pre-production). The program also manages version control and contributes to time management in the scheduling of content ready for pre-production.

6.3) Validation: content must be validated as meeting the exact requirements of the specifications. While a tight schedule of content delivery is essential in this process, the focus is largely on the development of content according to design specifications and quality control. The formative evaluation procedures are important to ascertain how the process can be improved and what are the implications of any changes. The lab has developed and validated a software program that allows for the tracking of content and is sharable with participants in the process across stages.

\subsection{Pre-Production:}

The focus of the pre-production stage builds upon the design specifications and content development stages in that 
the emphasis is on ensuring that all content is complete and fully meets the design specifications of the instructional design and technology requirements. At the pre-production stage, attention shifts to structuring content for graphic production and making the content ready for graphic designers. Interface designs must also be completed, plans for multimedia production must be in place, and a production schedule must be set. The scheduling has to take the sequencing of production tasks into consideration. The eDL tracking system, utilized in Stage 6.2 (Content Management) to trace the progress of work on every feature in the design, becomes a major planning tool in readiness for production. Although online products are easier to revise than products produced in traditional print formats, the linking, tagging, interface designs, and other technical procedures are so interrelated that once production begins, changes becomes significantly more expensive.

\subsection{Production:}

The eDL is subject to the same accountability as a commercial publisher in the setting of deliverable dates. An ideal approach is to postpone production on a product until all features of a product have been completed at the pre-production stage. However, in the development of BAIP lessons, we were able to make a determination on certain features that allowed some features to move into production ahead of others. All content must be validated to meet the design and production requirements before going into production.

\section{Stage 9.0 Pilot testing is applied to all content-based products.}

Depending on the nature of the product(s) developed, pilot testing is done in authentic settings. Testing of specific features may also involve third party evaluators. The eDL has experience in pilot testing at a national level (Meyen et al., 2002) as well as in more intense environments where end users are asked to engage in pilot testing as an extension of the development process. Such was the case with the BAIP lessons as the eDL worked to build a network of over 200 schools districts that assumed a partnership role through participation in an intense pilot test of the intervention products.

\section{Instructional Planning Using the BAIP Lesson Model}

The BAIP lesson format design includes five frameworks that incorporate elements shown to be essential for effective instruction: (a) Contextual, (b) Teaching, (c) Lesson, (d) Application, and (e) Extension (see Table 1 for the organization and overview of the five frameworks in the BAIP lesson model). Each framework will be described in detail.

Testing of the BAIP lesson plan model took two forms. The first was in the lesson writing stage, where teachers and subject-matter experts engaged in an iterative process of

\section{TABLE 1 Lesson Design Format}

\begin{tabular}{ll}
\hline Framework & Content Components \\
\hline Contextual Framework & $\begin{array}{l}\text { Standard } \\
\text { Benchmark } \\
\text { Indicator }\end{array}$ \\
Teaching Framework & Instructional Translation: \\
& Concept \\
& Skill \\
& Essential vocabulary \\
& Application \\
Lesson Framework & Prior Knowledge: \\
& Step-by-step review of \\
& prerequisite skills for the \\
& lesson \\
& Application: Connect to age- \\
& appropriate life experience \\
Model New Concept: \\
Concrete or semi- \\
\\
concrete example \\
Step-by-step demonstra- \\
tion/illustration \\
Practice: \\
Guided practice \\
Independent practice \\
Validation: \\
Reflection: Students \\
articulate their under- \\
standing of the indicator \\
and what they know \\
Assessment: Constructive \\
response item/open- \\
ended question
\end{tabular}

Extension Framework

Activities for students in need of enrichment

Activities for students with

learning disabilities

References

Instructional support:

Vocabulary

Handout

PowerPoint

writing lessons based on detailed research-based specifications. The second form of testing involved use of the lessons in classroom settings.

\section{Contextual Framework}

Each BAIP lesson begins with the contextual framework, which serves as an introduction to the lesson by stating the 
state standard, benchmark, and indicator the lesson will address (see Figure 2 for an example of the contextual framework).

\section{Teaching Framework}

The second framework of the lesson is the teaching framework. This framework is designed to enhance teachers' understanding of the standard that the lesson will address. Each teaching framework begins with an overview of the standard. The overview is written in language that is easy to understand. Next, the framework identifies and lists all of the prerequisite skills and concepts for the standard. The framework goes on to identify and list all of the skills or concepts that must be taught so that the student can master the standard. Finally, all of the mathematic terms that are essential to the lesson are listed and defined.

The Teaching Framework is an extremely important part of the lesson plan development process, as research has shown that $45 \%$ of special education teachers who teach math are not familiar with the NCTM standards (Maccini \& Gagnon, 2002). In addition, only 59\% of special education teachers feel confident in teaching the mathematics standards. Thus, in teaching instructional planning, it may be helpful not only to introduce teachers to the curriculum standards but also to teach them how to translate standards into instructional plans, as is done in the teaching framework of the BAIP lessons. The method used to translate curriculum standards during the BAIP development process was based on Elliott and Thurlow's (2000) backmapping approach. Backmapping ensures a match between standards and instruction by breaking standards down into instructional concepts and then writing instruction for each concept.

Using this approach, each lesson plan starts with the curriculum standard (which is identified in the Contextual Framework). Once the standard is identified, the standard is paraphrased. Next the standard is broken down into skills and concepts so that lesson writers can easily identify all of the instructional concepts that need to be addressed in the lesson. Once the standard is broken down into concepts and/or skills, the writer identifies the prerequisite concepts that are tied to the standard. The final step in the teaching framework is to identify and define all of the vocabulary terms that are essential to learning the prerequisite and standard concepts and skills (see Figure 3 for an example of the backmapping approach).

\section{Lesson Framework}

The third framework is the lesson framework. The lesson framework is comprised of the instructional components used to teach the prerequisite and standard concepts and/or skills. Each lesson framework includes instructional steps for concrete modeling and demonstration. In addition, each lesson framework has a corresponding PowerPoint presentation that can be used during classroom instruction. The lesson framework begins with instruction on the prerequisite concepts/ skills. The instruction is extremely thorough, as those developing the lessons are asked to reflect and document step-bystep instructions on how to teach the concepts and document the possible reactions students may have as a result of instruction. Consequently, each of the prior knowledge and standard concepts are described explicitly in terms of teacher prompts and corresponding student responses; such a format is often referred to as a scripted approach to lesson plan development. Lesson scripts are written narratives outlining what teachers should say to teach or convey academic information, questions teachers should ask their students, and the responses students should provide (Gunter \& Reed, 1997).

Using a lesson scripting approach for lesson plan development can lead to greater reflection on the instructional needs of students with disabilities. Research has found that students with disabilities often struggle with problem-solving tasks due to metacognitive processing deficits (Baxter,

\begin{tabular}{|c|c|}
\hline Frameworks & \multirow[b]{2}{*}{ Contextual Framework: view Explanation } \\
\hline 1. Contextual & \\
\hline II. Teaching & \multirow{7}{*}{$\begin{array}{l}\text { Standard: The student uses numerical and computational concepts and procedures in a variety of } \\
\text { situations. } \\
\text { Benchmark: Number Systems and Their Properties } \\
\text { Indicator: The student names, uses, and describes these properties with the real number system and } \\
\text { demonstrates their meaning including the use of concrete objects: (1) Symmetric Property of Equality (if } a= \\
b, \text { the } b=a \text { ), (2) Additive and Multiplicative Properties of Equality (if } a=b \text {, then } a+c=b+c \text { and if } a=b \text {, then } \\
a c=b c \text { ), and (3) Inequalities (if } a>b \text {, then } a+c>b+c \text { and if } a>b \text {, and } c>0 \text {, the } a c>b c \text { ). }\end{array}$} \\
\hline III. Lesson & \\
\hline IV. Application & \\
\hline V. Extension & \\
\hline Resources & \\
\hline Glossary & \\
\hline Download / Tools & \\
\hline References & - \\
\hline Credits & \\
\hline Help & \\
\hline
\end{tabular}

FIGURE 2.

A contextual framework and structure of BAIP lessons 


\section{Standard}

The student uses numerical and computational concepts and procedures in a variety of situations. In particular, the student names, uses, and describes associative, commutative, distributive, and substitution properties with the real number system and demonstrates their meaning using concrete objects.

\section{Backmapping}

Teaching Concepts: Students will gain an understanding of the three basic properties of mathematics (associative $[a+(b+$ $c)=(a+b)+c$ and $a(b c)=(a b) c]$, commutative $(a+b=b+a$ and $a b=b a)$, and distributive $[a(b+c)=a b+a c])$, including the substitution property (if $\mathrm{a}=2$, then $3 \mathrm{a}=3 \times 2=6$ ). They will understand its concepts and applications to solving equations.

\section{Students will:}

(1) identify and name the property in the expression;

(2) explain which laws hold for given operations and recognize when the laws do not hold;

(3) restate and simplify expression using properties;

(4) understand and demonstrate the concepts of algebraic properties for operations using addition, subtraction, multiplication, and division; and

(5) compute the expression by substituting the variable for the known number.

Prerequisite Skills and Concepts: Students need to understand the use of symbols, letters, and expressions to represent unknown variables, which is fundamental to algebra. Prior to starting this lesson, students should be introduced to the concept of variables in the form of symbols and letters. Students should understand that symbols and letters can represent missing numbers.

Although students have used basic math facts to solve equations, they may not be familiar with the concept of the basic rules of algebra. It is important that students know the order of operations for solving equations (parenthesis, exponents, multiplication, division, addition, and subtraction - PEMDAS). Students need to understand the concept of properties of numbers in mathematics, because they will become more relevant in advanced math.

\section{Essential Vocabulary:}

$\begin{array}{lll}\begin{array}{l}\text { expression } \\ \text { algebraic expression }\end{array} & \begin{array}{l}\text { constant } \\ \text { operation }\end{array} & \begin{array}{l}\text { distributive property } \\ \text { substitution property }\end{array} \\ \begin{array}{l}\text { order of operations } \\ \text { variable }\end{array} & \begin{array}{l}\text { associative property } \\ \text { commutative property }\end{array} & \end{array}$

\section{FIGURE 3. Backmapping}

Woodward, \& Olson, 2001; Montague \& van Garderen, 2008; Swanson, Hoskyn, \& Lee, 1999). The step-by-step process of lesson scripting provides teachers with the time to reflect on the instructional needs of students with disabilities and any metacognitive process deficits that students may have. Once the instructional needs or metacognitive process deficits are realized, teachers can add explicit instruction within the lesson script to address these deficits, as explicit instruction has been shown to help students become more proficient problem solvers (Montague \& van Garderen, 2008; Swanson, Hoskyn, \& Lee, 1999). Explicit instruction includes the following components: (a) administration of probes, (b) repeated feedback, (c) individualization, (d) step-by-step instruction, (e) pictorial diagrams, (f) smallgroup instruction, and $(\mathrm{g})$ direct questioning.

The scripted approach to lesson plan development and the addition of explicit instruction help to ensure that teachers are thinking about and providing instruction that is based on their students' experiences, ability, and knowledge levels. Moreover, by taking the time to reflect on students' strengths, weaknesses, and experiences, teachers are better prepared to develop lesson plans that are motivating and designed to capture students' interest (Robinson, Robinson, \& Maceli, 2000). See Figure 4 for an example of the lesson framework. 


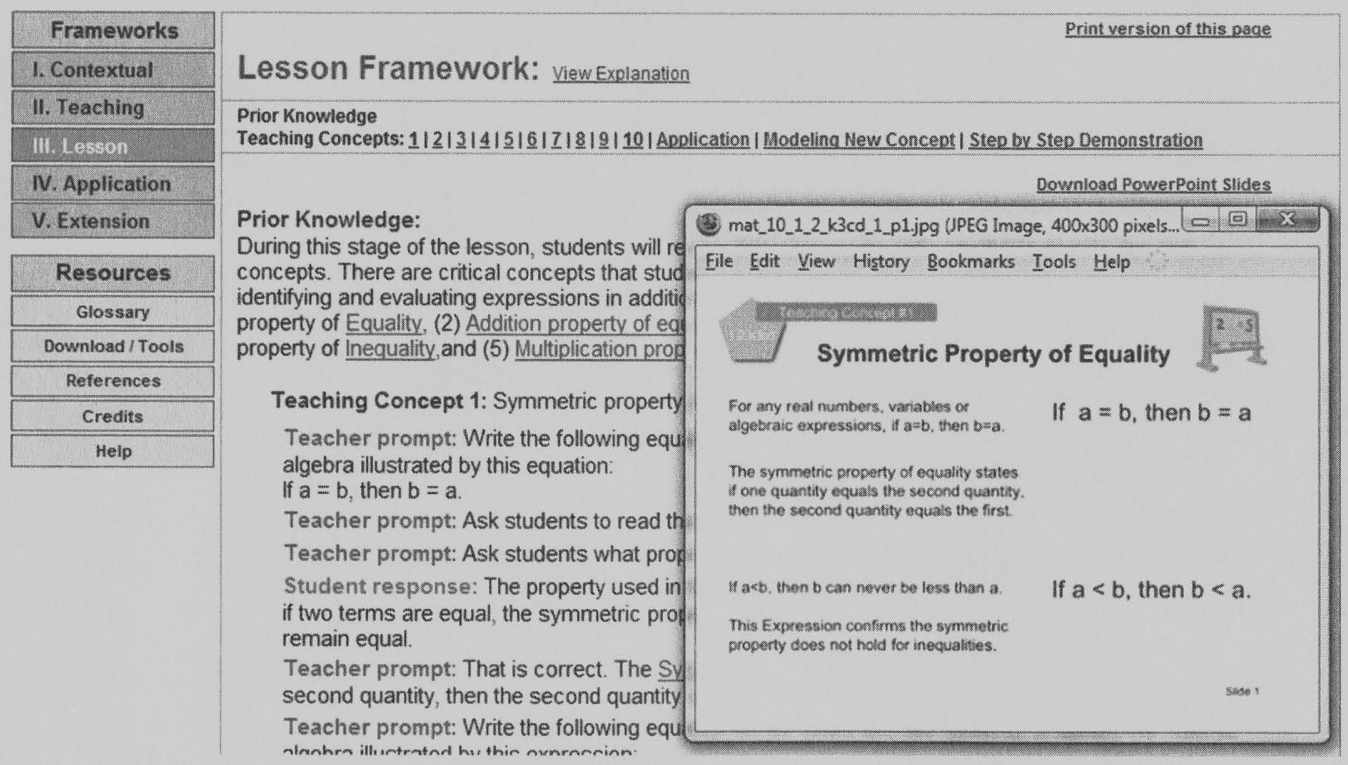

\section{FIGURE 4. Lesson Framework}

\section{Application Framework}

The fourth framework, the application framework, provides both guided and independent practice through the development of worksheets and/or activities (See Figure 5 for an example of the application framework). Each worksheet begins with guided practice in which the lesson writers create and solve several mathematic problems using the teacher prompt/student response format. Starting each worksheet with guided practice requires teachers to have a thorough understanding of the concepts they have taught, as they are responsible for explaining how to solve mathematic questions that are tied to their instruction. This approach ensures that teachers thoroughly understand the concepts and the questions they are asking, which in turn builds a teachers' confidence level in solving and answering mathematic problems during classroom instruction.

According to research, effective instruction includes guided practice, correction and feedback, independent practice, and weekly or monthly review. Several research studies have extended and supported the instructional planning components first identified and compiled by Rosenshine and Stevens in 1986 (Maccini, McNaughton, \& Ruhl, 1999; Maccini \& Ruhl, 2000; Mercer \& Miller, 1992). Rosenshine and Stevens' original work was based on a review of 100 correlation and experimental studies that examined instructional components leading to effective instruction. Since then, Maccini and Ruhl (2000) have incorporated modeling, guided practice, independent practice, and feedback to teach secondary students with learning disabilities a strategy designed to improve their problem-solving abilities.

In addition to guided and independent practice, the application framework incorporates three types of validation questions that can be used at any time during classroom instruction. The formats of the validation questions are concrete, open-ended, and reflective. By requiring teachers to think about and create validation questions prior to classroom instruction, teachers are prepared to gauge student understanding and knowledge throughout instruction.

\section{Extension Framework}

The last framework, the extension framework, provides additional suggestions and activities for students with learning disabilities and students in need of academic enrichment. These activities range from concrete to abstract (See Figure 6 for an example of the extension framework). By including additional instruction for students with disabilities, teachers have to take the time to reflect on their students' instructional needs prior to classroom instruction. Often, addressing the instructional needs of students with disabilities during lesson plan development results in more collaboration, as teachers seek out and work with others to obtain additional instructional strategies and material. Moreover, teachers enter the classroom feeling prepared to meet the instructional needs of all students. 


\begin{tabular}{|c|}
\hline \multicolumn{1}{|c|}{ Frameworks } \\
\hline \hline I. Contextual \\
\hline II. Teaching \\
\hline III. Lesson \\
\hline IV. Appilcation \\
\hline V. Extension \\
\hline Resources \\
\hline Glossary \\
\hline \hline Download/Tools \\
\hline References \\
\hline Credits \\
\hline Help \\
\hline \\
\hline
\end{tabular}

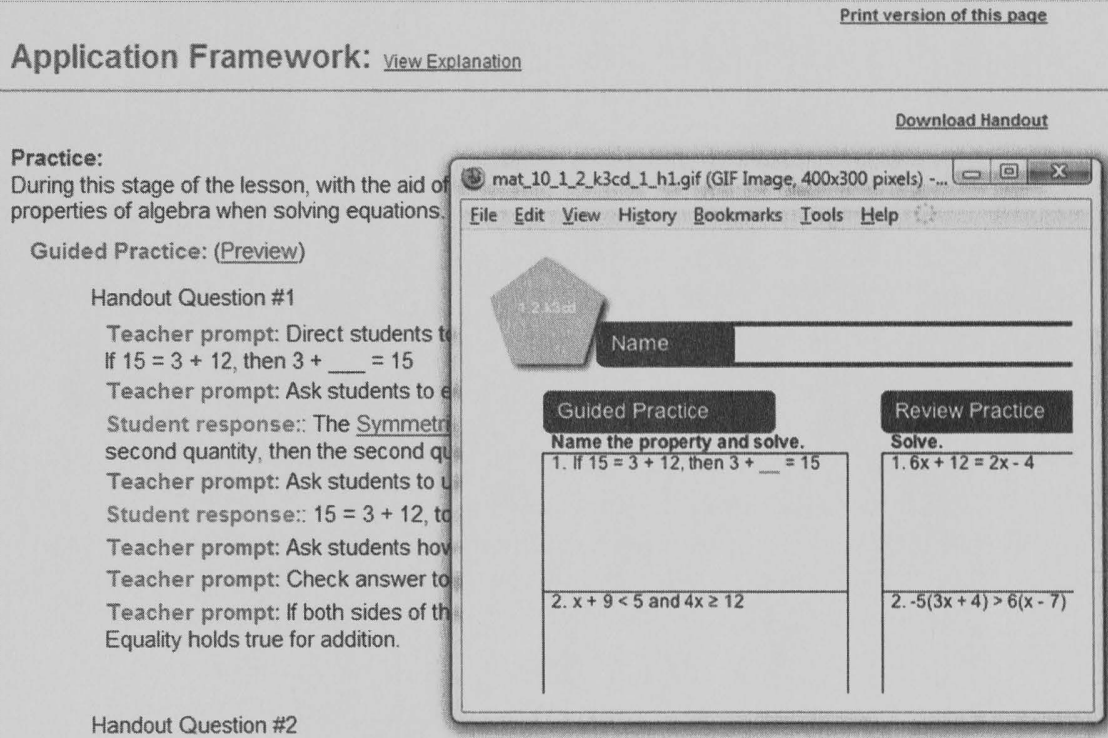

FIGURE 5. Application Framework

\begin{tabular}{|c|}
\hline Frameworks \\
\hline I. Contextual \\
\hline II. Teaching \\
\hline III. Lesson \\
\hline IV. Application \\
\hline V. Extension \\
\hline Resources \\
\hline Glossary \\
\hline \hline Download/Tools \\
\hline \hline References \\
\hline \hline Credits \\
\hline Help \\
\hline
\end{tabular}

Help

\section{Extension Framework: view Explanation}

Print version of this page

Activities for Students in Need of Enrichment:

One way to provide students with enrichment activities is to group students into small groups and have them solve real-life equation problems using the basic properties of algebra. An example of a problem that could be solved using these properties is:

Connor's homework average in Math class is 93 . The test average is $3 / 4$ of the final grade and the homework average is $1 / 4$ of the final grade. What test average does Connor need in order to have a final grade of at least 80 ?

Equation: $80 \leq 1 / 4(93)+3 / 4 t$

\section{Activities for Students with Special Learning Needs:}

Review the teaching concepts of the variables, equations and order of Operation with the students to ensure that the student has mastered crucial knowledge skills related to basic properties of algebra.

Review all key vocabulary terms and definitions to ensure that student can recognize, read and define these terms when that are encountered in the lesson.

FIGURE 6. Extension Framework

\section{Use of the Lesson Format by BAIP Lesson Writers}

During the BAIP lesson plan development efforts, writers reported that they believed that the structured approach to lesson plan development improved their knowledge of mathematic standards. In addition, teachers reported that the backmapping approach helped them realize the instructional complexity and depth of curriculum standards. This is important, as awareness of the breadth and depth of instruction in mathematics can help address one of the main criticisms of mathematics instruction in the United States - that is, claims that fragmented mathematic instruction has led to unsatisfactory mathematics learning in United States schools (Ball, 2003; Ma, 1999). Through the backmapping approach, teachers writing the BAIP lessons addressed fragmentation as they identified and planned instruction for all of the prerequisite skills and concepts for each standard. Moreover, many of the lesson writers for the BAIP project chose to work with colleagues at a grade level below the target lesson audience to ensure that they identified and planned age-appropriate 
instruction for all of the prerequisite and standard concepts and skills. In addition, many writers submitted their backmapping process for review, which resulted in additional advice and guidance regarding the skills and concepts that needed to be addressed throughout the lesson.

The authors of this paper found that the skill of writing lesson scripts was central to effective planning and teaching. Developing lesson scripts helped writers begin to understand students as learners. It caused writers to think deeply about the knowledge students bring to the classroom and plan instruction accordingly. In addition, through the scripting process (teacher prompt/student response format), writers realized where instruction could possibly lead and thus developed lessons with greater depth of content coverage. In fact, many of the BAIP writers shared that following a scripted process made them seek out additional content knowledge and resources that broadened their instruction. They believed that such a thorough approach to lesson plan development led to deeper reflection on the concepts and instruction. Moreover, writers felt more confident in teaching the mathematic concepts, as they felt they were well prepared for questions that may arise during classroom instruction. Thus, by creating a lesson script, BAIP lesson writers spent more time planning and acquiring content knowledge than they may have done otherwise.

\section{Lessons Learned Through the BAIP Lesson Writing/Testing Process}

The observations shared in this paper derive from the authors working with approximately 100 classroom teachers in writing lesson scripts in the BAIP lesson format. The authors have also conducted professional development sessions during the testing of the BAIP that focused on the development and use of BAIP lessons. In addition, the authors collected data on the pedagogical value and use of each lesson component through periodic fidelity surveys as well as through an annual survey. Additionally, an online system for routine teacher feedback is continually available and monitored. The BAIP Bulletin, an electronic newsletter, is used to provide feedback to teachers and administrators on each lesson modification. This occurs on a bi-monthly basis.

Experienced teacher educators and staff development specialists may find the lessons learned through the BAIP lesson model helpful in determining how the model generalizes to their work with experienced and/or inexperienced teachers. Thus, the authors provide a list of observations based on the lesson writing process and testing the BAIP lessons in mathematics:

1. Elementary teachers, selected as writers, tended initially to write activities rather than translate concepts into instructional options. The activities were well written but lacked instructional focus. In contrast, middle and secondary teachers focused on developing teaching concepts. The differences found between the elementary and the middle and high school lessons were interpreted as resulting from differences in teacher preparation.

2. Lesson writers learned quickly from the iterative process as they worked with subject matter experts to write lessons. Thus, it did not take long for writers to become proficient in the lesson writing process. One might assume that pre-service teachers, with the appropriate instructional support, would show the same progress.

3. Writers at all levels of experience tended to do well in developing directed instruction and guided practice components of the lesson design.

4. Experienced teachers valued the prior knowledge component of the lesson design. Thus, writers placed high importance on teachers' awareness of students' prior skills and knowledge related to the respective standard and recording it as part of the planning process. This also proved to be a learning process, as teachers were able to confirm their assessment of a students' prior knowledge as the student responded to the lessons.

5. The essential vocabulary identified by the writers was integrated throughout the lessons and proved helpful to teachers in implementing lessons. The total essential vocabulary included 740 terms across all standards covered in BAIP.

6. While teachers were very effective in identifying the essential vocabulary, there was considerable variance in the terms used by the writers in describing mathematical operations at the elementary level. This required editing to correct and to ensure consistency in the terms used. It has also resulted in the development of an online dictionary of essential vocabulary that relies heavily on graphics and animations. Mathematics is like science in that there is a language of mathematics that both students and teachers need to understand to maximize learning.

7. Writers expressed strong support for the lesson model design. Most writers wrote at least three lessons. Each lesson was very comprehensive and detailed. All of the lesson writers received feedback from subject-matter experts as they worked to meet the quality-control requirements for lessons. This feedback process was similar to what a teacher educator might provide pre-service students.

8. The emphasis on embedding content along with teaching techniques in the frameworks reportedly enhanced teachers' content knowledge.

9. Writing lessons against a research-based model is initially difficult but ultimately effective. Teachers 
on the writing teams, while knowledgeable about the lesson design features, were not experienced in the actual process of writing lessons in the detail and format required by the BAIP instructional design. This resulted in the need for additional training and implementation of a systematic review process focusing on content accuracy and compliance with the instructional design.

10. It is easier to write activities than teach concepts. This became particularly apparent in the development of lessons for grades $3,4,5$, and 6 , which involved experienced elementary teachers. It was not as evident at the middle and secondary grades. The reason for this difference seems to be related to teachers' pre-service preparation. That is, elementary teachers are prepared to teach a wide array of subjects, including mathematics, whereas at the middle and secondary levels, teachers who teach math are typically certified to be math educators.

11. It is important to focus on teaching concepts to ensure that standards are understood and that writers are successful in making the translation into instructional practices. This was reinforced through the backmapping approach and the feedback provided to writers by the subject-matter experts during the review process.

12. Aligning teaching concepts with applied examples is important to teachers as they implement BAIP lessons. This became apparent during the content development stage of creating the lessons, where the lesson writing teams provided formative input about their perceptions of the instructional design. The team environment can easily be replicated in a preservice class or in professional development.

13. Based on 781 teacher responses to the 2009 fidelity research currently underway, the following lesson components were ranked identically in terms of frequency of use and frequency modified.

1. Guided practice

2. Worksheets

3. PowerPoint slides

4. Prior knowledge teaching concepts

5. Content coverage of standard/indicator

While the lessons are designed in detail, they are also designed so that users can modify any component of a lesson to meet the needs of individual students.

\section{SUMMARY}

During the development and testing of the Blending Assessment With Instruction Program (BAIP) over the past five years, the authors worked with master teachers and subject-matter experts. They also had access to input from teachers with diverse backgrounds and experience. The authors paid close attention to fidelity issues specific to teaching lessons and student outcomes while carrying out field testing. Over 100 teachers were trained statewide on the lesson-writing format. The BAIP development, training, and implementation experiences dramatically changed the authors' perspectives on the instructional planning skills teachers require in order to meet the instructional needs of students with learning disabilities. As the authors moved through development and into field testing of the BAIP, it became apparent that the preparation of teachers in special education should be revisited. Emphases on collaboration, accommodation, and assessment, while important, may not be sufficient, because special education teachers are disadvantaged if they are not prepared to meet the accountability expectations that now exist in the teaching profession. Thus, a stronger emphasis on content knowledge across subject fields appears to be needed.

The experiences acquired through the BAIP development process have led the authors to offer the following suggested objectives for preparing special education teachers to fulfill their responsibilities in meeting the instructional needs of students with learning disabilities. Special education teachers must be prepared to:

1. understand the mathematic concepts they will be responsible for teaching;

2. translate curriculum standards (or concepts) into lesson scripts;

3. align instruction with curriculum standards;

4. identify required prior knowledge of students for learning specific new concepts;

5. understand the relationship between curriculum standards, instruction, and state assessments; and

6. apply the elements of effective instruction (e.g., review, presentation, guided practice, corrections and feedback, independent practice, and weekly and monthly reviews).

BAIP development efforts have now moved into the area of science, and it appears evident at this time that the same objectives generalize across both content areas. The assumption that the objectives are achieved at the pre-service level by requiring courses from general education was not evident in the authors' experiences. Instead, the authors believe that there must be a strong commitment on the part of special education faculty to work very closely with subject-matter faculty to ensure that pre-service teachers majoring in special education are held to a high level of expectation in instructional planning and content knowledge. The 
challenge is for special education teacher educators to reassess what they do and determine whether they concur with these observations. If they do, then they may need to examine how these objectives will be met.

This work is supported in part by the Center for Education Testing and Evaluation at the University of Kansas, the Kansas State Department of Education, and the National Science Foundation.

\section{REFERENCES}

Aust, R. J., \& Meyen, E. (2005). The design and development of a scaleable e-learning authoring system. In V. Uskow (Ed.), Webbased education - 2005 (Proceedings of the fourth IASTED International Conference). Anaheim, CA: ACTA Press.

Ball, D. L. (2003, February). Mathematics in the 21st century: What mathematical knowledge is needed for teaching mathematics? Paper presented at the Secretary's Summit on Mathematics: Washington, DC.

Ball, D. L., Hill, H. C., \& Bass, H. (2005). Knowing mathematics for teaching: Who knows mathematics well enough to teach third grade, and how can we decide? American Educator, 29(3), 14-22, 43-46.

Baroody, A. J. (2003). The development of adaptive expertise and flexibility: The integration of conceptual and procedural knowledge. In A. J. Baroody \& A. Dowker (Eds.), The development of arithmetic concepts and skills: Constructing adaptive expertise studies (pp. 1-34). Mahwah, NJ: Erlbaum.

Baxter, J. A., Woodward, J., \& Olson, D. (2001). Effects of reformbased mathematics instruction on low-achievers in five third grade classrooms. The Elementary School Journal, 101(5), 529-547.

Borko, H., \& Whitcomb, J. A. (2008). Teachers, teaching, and teacher education: Comments on the national mathematics advisory panel's report. Educational Researcher, 37(9), 565-572.

Brownell, M. T., Hirsch, E., \& Seo, S. (2004). Meeting the demand for highly qualified special education teachers at a time of severe shortages: What should policymakers consider? Journal of Special Education, 38, 56-61.

Elliott, J. L., \& Thurlow, M. L. (2000). Educational accountability: What is it? In J. L. Elliott \& M. L. Thurlow (Eds.), Improving test performance of students with disabilities . . . on district and state assessments (pp. 10-34). Thousand Oaks, CA: Corwin Press.

Fuson, K., Stigler, J. W., \& Bartsch, K. (1989). Grade placement of addition and subtraction topics in Japan, Mainland China, the Soviet Union, and the United States. Journal for Research in Mathematics Education, 19(5), 449-456.

Goldhaber, D. D., \& Brewer, D. J. (2000). Does teacher certification matter? High school teacher certification status and student achievement. Educational Evaluation and Policy Analysis, 22, 129-145.

Goldhaber, D. D. (2002). The mystery of Good Teaching. Education Next, 2(1), 50-55.

Graham, K. J., \& Fennell, F. (2001). "Principles and standards for school mathematics" and teacher education: Preparing and empowering teachers. School Science and Mathematics, 101(6), 319-327.

Gunter, P. L., \& Reed, T. M. (1997). Academic instruction of children with emotional and behavioral disorders using scripted lessons. Preventing School Failure, 42, 33-37.
Hill, H. C., Rowan, B., \& Ball, D. L. (2005). Effects of teachers' mathematical knowledge for teaching on student achievement. American Educational Research Journal, 42(2), 371-406.

Institute of Education Sciences (IES). (2007). Mathematic achievement of fourth and fifth Graders in 2007. TIMSS 2007 results. Retrieved April 20, 2009, from http://nces.ed.gov/timss/results 07_math07.asp

Ma, L. (1999). Knowing and teaching elementary mathematics: Teachers' understanding of fundamental mathematics in China and the United States. Mahwah, NJ: Erlbaum.

Maccini, P., \& Gagnon, J. C. (2002). Perceptions and applications of NCTM standards by special and general education teachers. Exceptional Children, 68(3), 325-344.

Maccini, P., McNaughton, D., \& Ruhl, K. L. (1999). Algebra instruction for students with learning disabilities: Implications from a research review. Learning Disability Quarterly, 22(2), 113-126.

Maccini, P., \& Ruhl, K. L. (2000). Effects of a graduated instructional sequence on the algebraic subtraction of integers by secondary students with learning disabilities. Education and Treatment of Children, 23, 465-489.

Mercer, C. D., \& Miller, S. P. (1992). Teaching students with learning problems in math to acquire, understand, and apply basic math facts. Remedial and Special Education, 13(3), 19-35.

Meyen, E. L., Aust, R. J., Bui, Y. N., Ramp, E., \& Smith, S. J. (2002). The online academy formative evaluation approach to evaluating online instruction. Internet and Higher Education, 5(2), 89-108.

Miller, S. P., \& Hudson, P. J. (2006). Helping students with disabilities understand what mathematics means. Teaching Exceptional Children, 39(1), 28-35.

Montague, M., \& van Garderen, D. (2008). Effective mathematics instruction. In R. J. Morris \& N. Mather (Eds.), Evidence-based interventions for students with learning and behavioral challenges (pp. 236-257). New York: Routledge.

No Child Left Behind Act of 2001, 20 U.S.C. $\$$ 6301, et seq. (2007).

Robinson, E., Robinson, M., \& Maceli, J. C. (2000). The impact of standards-based instructional materials in mathematics in the classroom. In M. J. Burke \& F. R. Curcio (Eds.), Learning mathematics for a new century (pp. 112-126). Reston, VA: National Council of Teachers of Mathematics.

Shen, J., Popink, S., Cui, Y., \& Fan, G. (2007, Summer). Lesson planning: A practice of professional responsibility and development. Educational HORIZONS, 248-258.

Shulman, L. S. (1987). Knowledge and teaching: Foundations of the new reform. Harvard Educational Review, 57(1), 1-22.

Swanson, H. L., Hoskyn, M., \& Lee, C. (1999). Interventions for students with learning disabilities: A meta-analysis of treatment outcomes New York: Guilford Press.

Thompson, P. W. (2008). On professional judgment and the National Mathematics Advisory Panel Report: Curricular content. Educational Researcher, 37, 582-587.

U.S. Department of Education. Institute of Education Sciences, National Center of Education Statistics (NCES). (2007). NAEP Data Explorer. Retrieved April 7th, 2009, from http://nces.ed.gov/nations reportcard/naepdata/dataset.aspx

Wayne, A. J., \& Youngs, P. (2003). Teacher Characteristics and Student Achievement Gains: A Review. Review of Educational Research, 73(1), 89-122. 